\title{
Criteria for Identifying an Astronomer as an Amateur
}

\author{
Thomas $R$. Williams
}

3621 Wakeforest, Houston, TX 77098-5509, U.S.A.

While significant contributions of amateur astronomers are generally recognized in the literature, the identification of the individual as an amateur is frequently unclear. As a result, amateur astronomers today have a limited sense of the contributions of earlier amateur astronomers. In part, this problem stems from current usage of the word "amateurish" as a pejorative, representing something not well-done or lacking in quality. In addition, many individuals, who take pride in identifying themselves as amateur astronomers are neither inclined, nor in fact capable, of making a contribution to astronomy. It is important, however, for historians and others who write about the history of astronomy to recognize amateur astronomers and identify the significance of their contributions. For it is through such elaboration that other amateurs will recognize the possibilities and great value that may be associated with their own efforts. Therefore it is necessary to develop a common understanding of the characteristics that distinguish an amateur astronomer from what I identify in this paper as a "recreational sky observer". Such a classification scheme should help future writers to correctly identify amateur astronomers and their contributions.

In considering the term "amateur astronomer", I focus on the fact that one must first qualify as an astronomer. Only then is it possible to consider further classification as an amateur or a professional. From dictionary definitions the following statement may be derived: An astronomer is a person who is very skillful or highly trained and informed in that branch of knowledge concerned with establishing and systematizing facts, principles and methods, and with conduction experiments and observations in order to develop hypotheses and systematized knowledge about the nature or principles of the stars, planets and all other heavenly bodies, dealing with their composition, motion, relative position, size and other properties.

With this definition in mind several criteria may be developed to classify an individual as an astronomer and to thereby differentiate him from a recreational observer: (1) A serious intent must be displayed to contribute to the advancement of astronomy by providing information that is needed and might otherwise not be available to other astronomers; (2) These efforts must extend over a period of time, either by routine observations, or through discovery or search work which can be either theoretical or observational; (3) Acceptable methods or techniques must be used considering the intended application of the data; and (4) The results of this work should be communicated to other astronomers. 
Consideration may now be given to characteristics which differentiate professionals and amateurs. A professional is a person who engages in some art, science, sport, etc. for his livelihood. An amateur is a person who engages in some art, science, sport, etc. for the pleasure of it rather than for money. The question of whether one is paid or not becomes the critical issue in differentiating between the professional and the amateur. The amateur is likely to derive his income from other means than astronomy. Most amateur astronomers lack the theoretical training of the professional. Without that common language, it is difficult for them to communicate about the questions that need answering, even though the answers may be within the amateur's grasp. Yet amateur astronomers frequently excel in observational astronomy and have much to offer in terms of their dedication to extensive routine observation.

While recreational sky observers appreciate the beauty of the night sky, they are not motivated to contribute to the science. Their skills may be significant in locating and identifying faint or small objects, even occasionally a comet or nova. However, their routine usually includes re-observation of the Messier Catalogue or checking the colors of bright double stars. "Armchair" astronomers who take pleasure in reading everything available about astronomy are also included in this group.

The key to differentiating between recreational sky observers and astronomers, whether amateur or professional, is in observing that astronomy is work, that certain features of this work fit a recognizable pattern constituting the practice of astronomy, and that individuals who do not work within these recognizable patterns should not be considered astronomers, amateur or otherwise. These criteria should facilitate the identification of amateur astronomers, who attempt to make significant contributions to astronomy. Identification of amateur astronomers will restore an appreciation of the past contributions made by amateur astronomers, and will encourage current and future efforts by amateurs for the advancement of astronomy.

\section{Reference}

Williams, T.R.: Criteria for selection of an astronomers as an amateur, Abstract 51.11, Bull. Amer. astron. Soc., 16 (2), 1984 